\title{
Metabolome- and genome-scale model analyses for engineering of Aureobasidium pullulans to enhance polymalic acid and malic acid production from sugarcane molasses
}

\author{
Jun Feng ${ }^{1 \dagger}$, Jing Yang ${ }^{1 \dagger}$, Wenwen Yang ${ }^{1}$, Jie Chen ${ }^{2,3}$, Min Jiang $^{4}$ and Xiang Zou ${ }^{1 *}$ (1)
}

\begin{abstract}
Background: Polymalic acid (PMA) is a water-soluble biopolymer with many attractive properties for food and pharmaceutical applications mainly produced by the yeast-like fungus Aureobasidium pullulans. Acid hydrolysis of PMA, resulting in release of the monomer L-malic acid (MA), which is widely used in the food and chemical industry, is a competitive process for producing bio-based platform chemicals.

Results: In this study, the production of PMA and MA from sucrose and sugarcane molasses by A. pullulans was studied in shake flasks and bioreactors. Comparative metabolome analysis of sucrose- and glucose-based fermentation identified 81 intracellular metabolites and demonstrated that pyruvate from the glycolysis pathway may be a key metabolite affecting PMA synthesis. In silico simulation of a genome-scale metabolic model (iZX637) further verified that pyruvate carboxylase (pyc) via the reductive tricarboxylic acid cycle strengthened carbon flux for PMA synthesis. Therefore, an engineered strain, FJ-PYC, was constructed by overexpressing the pyc gene, which increased the PMA titer by $15.1 \%$ compared with that from the wild-type strain in a 5-L stirred-tank fermentor. Sugarcane molasses can be used as an economical substrate without any pretreatment or nutrient supplementation. Using fed-batch fermentation of FJ-PYC, we obtained the highest PMA titers $(81.5,94.2 \mathrm{~g} / \mathrm{L}$ of MA after hydrolysis) in $140 \mathrm{~h}$ with a corresponding MA yield of $0.62 \mathrm{~g} / \mathrm{g}$ and productivity of $0.67 \mathrm{~g} / \mathrm{L} \mathrm{h}$.
\end{abstract}

Conclusions: We showed that integrated metabolome- and genome-scale model analyses were an effective approach for engineering the metabolic node for PMA synthesis, and also developed an economical and green process for PMA and MA production from renewable biomass feedstocks.

Keywords: Aureobasidium pullulans, Metabolic engineering, Polymalic acid, Pyruvate carboxylase, Sugarcane molasses

*Correspondence: zhx1030@swu.edu.cn

†Jun Feng and Jing Yang contributed equally to this work

${ }^{1}$ College of Pharmaceutical Sciences, Chongqing Engineering Research

Center for Pharmaceutical Process and Quality Control, Southwest

University, 2 Tian Sheng Road, Beibei, Chongqing 400715, People's

Republic of China

Full list of author information is available at the end of the article 


\section{Background}

Polymalic acid (PMA) is a water-soluble biopolymer composed of L-malic acid (MA) monomers and is mainly produced by the yeast-like fungus Aureobasidium pullulans [1]. PMA has free carboxyl groups, making it simple to perform chemical modifications and create various derivatives or carrier-linked pro-drugs. Due to its unique properties, including high water solubility, biocompatibility, and biodegradability, PMA has attracted an increasing attention as a drug carrier or biomaterial in the past few years and is expected to have applications in the preparation of various polymeric micelles, microparticles, nanoconjugates, and nanoparticles for drug delivery systems [2-5]. PMA also has the potential to be used as a nano-imaging agent for safe and noninvasive diagnosis in the clinical setting [6]. In addition, its monomer MA can be easily generated from PMA via acid hydrolysis. Like other dicarboxylic acids, MA is also an important organic acid and is regarded as a $\mathrm{C} 4$ platform chemical in the food and pharmaceutical industries, for which there is a strong global market of over 600,000 tons/year, with an annual growth rate of $4 \%[7,8]$.

Inexpensive renewable feedstocks and media for fermentation, as well as high PMA titers with good productivity are also important constraints in developing industrial PMA fermentation processes. The previous studies have demonstrated fermentative production of PMA from low-cost substrates, such as sweet potato [9], corncob [10, 11], soy molasses [12], and wheat straw [13]. However, starchy and lignocellulosic feedstocks must first be subjected to thermochemical, dilute acid, or enzymatic treatments to release fermentable sugars; these limitations must be overcome to achieve an economically competitive process, including enhanced strain tolerance and fermentation performance in the presence of inhibitors released from dilute acid-pretreated lignocellulose [8].

In this study, we aimed to develop an economical and environmentally friendly bioprocess for PMA and MA production from sugarcane molasses as a feedstock. Sugarcane molasses is the main by-product of sugar production and contains $\sim 50 \%$ reducing sugars, mainly sucrose and some glucose and fructose; in addition, sugarcane molasses can be used directly in fermentation without requiring any pretreatment $[14,15]$, and its price is $\sim 40 \%$ lower than corn (starch and dextrose) based on the fermentable sugar content according to the current market prices. Therefore, sugarcane molasses is considered a relatively inexpensive and renewable biomass feedstocks for biorefinery applications due to its rich sugar content and cost-effectiveness. As omics analysis developing rapidly over the last decade, metabolome analysis has been employed to characterize intracellular metabolic states for understanding cell metabolism and improving the production of target metabolites [16]. Metabolomics has been a powerful tool for understanding the intracellular metabolism with broad range of applications in various fields, including medical science [17], synthetic biology [18], medicine [19], plant systems [20], and microbial systems [21]. In this study, we evaluated the performance of the strain Aureobasidium pullulans for the utilization of different sugars, including sucrose, fructose, and glucose contained in sugarcane molasses, and compared the metabolic processes of sucrose- and glucose-based fermentation through metabolome analysis. In silico simulation of a genome-scale model of $A$. pullulans was further verified, and the metabolic node containing pyruvate carboxylase via the reductive tricarboxylic acid (TCA) cycle was engineered to enhance PMA production. Finally, direct sugarcane molasses fermentation, without any pretreatment or nutrient supplementation, was developed for PMA production. This work will be beneficial for the development of an economical and green process for PMA and bio-based MA production from renewable biomass feedstocks.

\section{Methods}

\section{Strains, media, and culture conditions}

The strain A. pullulans CCTCC M2012223 was isolated by our laboratory and can be obtained from the China Center for Type Culture Collection (Wuhan, China). This strain was maintained on potato dextrose agar slants. The seed culture medium contained $60-\mathrm{g} / \mathrm{L}$ glucose, 2-g/L N $\mathrm{NH}_{4} \mathrm{NO}_{3}, 0.1-\mathrm{g} / \mathrm{L} \mathrm{KH}_{2} \mathrm{PO}_{4}, 0.1-\mathrm{g} / \mathrm{L} \mathrm{MgSO}_{4}, 0.1-\mathrm{g} / \mathrm{L}$ $\mathrm{ZnSO}_{4}, 0.5-\mathrm{g} / \mathrm{L} \mathrm{KCl}$, and $20-\mathrm{g} / \mathrm{L} \mathrm{CaCO}_{3}$. The seed culture was grown in a $500-\mathrm{mL}$ shake flask containing $50-\mathrm{mL}$ liquid medium and incubated at $25{ }^{\circ} \mathrm{C}$ on a rotary shaker (180 rpm) for 2 days. The fermentation medium contained 90-g/L sugar (glucose, sucrose, xylose, arabinose, or fructose), 2-g/L N $\mathrm{NH}_{4} \mathrm{NO}_{3}, 0.1-\mathrm{g} / \mathrm{L} \mathrm{KH}_{2} \mathrm{PO}_{4}, 0.1-\mathrm{g} / \mathrm{L}$ $\mathrm{MgSO}_{4}, 0.1-\mathrm{g} / \mathrm{L} \mathrm{ZnSO}_{4}, 0.5-\mathrm{g} / \mathrm{L} \mathrm{KCl}$, and $20-\mathrm{g} / \mathrm{L} \mathrm{CaCO}_{3}$. Escherichia coli $\mathrm{DH} 5 \alpha$ cells were employed for routine DNA manipulations. E. coli was grown in LB medium $(5 \mathrm{~g} / \mathrm{L}$ yeast extract, $10 \mathrm{~g} / \mathrm{L}$ tryptone, $10 \mathrm{~g} / \mathrm{L} \mathrm{NaCl}, \mathrm{pH}$ $7.0)$ at $37{ }^{\circ} \mathrm{C}$, and kanamycin or ampicillin $(50 \mathrm{mg} / \mathrm{L})$ was added when required. Agrobacterium tumefaciens AGL1 was grown on YEB medium $(10-\mathrm{g} / \mathrm{L}$ yeast extract, $5-\mathrm{g} / \mathrm{L}$ tryptone, $5-\mathrm{g} / \mathrm{L}$ sucrose, $0.5-\mathrm{g} / \mathrm{L} \mathrm{MgSO}_{4}{ }^{7} 7 \mathrm{H}_{2} \mathrm{O}, \mathrm{pH} 7.0$ ) at $28{ }^{\circ} \mathrm{C}$, and kanamycin or carbenicillin $(50 \mathrm{mg} / \mathrm{L})$ was added when required.

\section{Sampling, quenching, and extraction of intracellular metabolites}

The cells of strain A. pullulans CCTCC M2012223 were collected after culturing for 48 and $72 \mathrm{~h}$ with glucose- and sucrose-based fermentation, respectively, and 
intracellular metabolism was quenched by immediately adding five volumes of prechilled $60 \%(\mathrm{v} / \mathrm{v})$ methanol. After quenching at $-40{ }^{\circ} \mathrm{C}$, cells were pelleted in a centrifuge $\left(4000 \times g, 4{ }^{\circ} \mathrm{C}, 10 \mathrm{~min}\right)$. The pellets were washed with phosphate-buffered saline ( $\mathrm{pH}$ 7.4), frozen in liquid nitrogen, and stored at $-80^{\circ} \mathrm{C}$. Next, $60 \mathrm{mg}$ per sample with six biological replicates was ball-milled into a fine powder under frozen conditions with $1 \mathrm{~mL}$ of extraction mix consisting of deionized water (50\%), methanol (50\%), and the internal standards nonadecanoic acid $(0.2 \mathrm{mg} /$ $\mathrm{mL}$ ) and isotope alanine $(10 \mathrm{mM})$, and then lyophilized. The samples were derivatized by vortexing with $60 \mu \mathrm{L}$ of $15-\mathrm{mg} / \mathrm{mL}$ methoxypyridine hydrochloride for $30 \mathrm{~s}$ and then incubating for $2 \mathrm{~h}$ at $37{ }^{\circ} \mathrm{C}$. The samples were then trimethylsilylated by adding $60-\mu \mathrm{L}$ bis(trimethylsilyl) trifluoroacetamide (BSTFA) with $1 \%$ trimethylchlorosilane and incubating for $90 \mathrm{~min}$ at $37{ }^{\circ} \mathrm{C}$. Subsequently, an extract containing all intracellular metabolites was collected via centrifugation at $12,000 \times g$ for $10 \mathrm{~min}$ at $4{ }^{\circ} \mathrm{C}$ [22].

\section{Metabolite detection with gas chromatography-mass spectrometry (GC-MS)}

GC-MS analysis was performed to detect the metabolites in the samples. Briefly, $1 \mu \mathrm{L}$ sample was injected into an Agilent 7890A/5975C GC-MS system (Agilent Technologies, CA, USA) with a 20:1 split injection ratio. The system was equipped with an HP-5MS capillary column (5\% phenyl methyl silox: $30 \mathrm{~m} \times 250 \mu \mathrm{m}$ i.d., $0.25 \mu \mathrm{m}$; Agilent J\&W Scientific, Folsom, CA, USA). The inlet temperature was maintained at $280^{\circ} \mathrm{C}$, the interface temperature was $150{ }^{\circ} \mathrm{C}$, and the ion source temperature was $250^{\circ} \mathrm{C}$. The $\mathrm{GC}$ temperature program was as follows: hold at $70{ }^{\circ} \mathrm{C}$ for $2 \mathrm{~min}$, ramp at $10{ }^{\circ} \mathrm{C} / \mathrm{min}$ to $300^{\circ} \mathrm{C}$, and a final hold at $300{ }^{\circ} \mathrm{C}$ for $5 \mathrm{~min}$. Helium was used as carrier gas at a constant flow rate of $1 \mathrm{~mL} / \mathrm{min}$, with a total run time of $30 \mathrm{~min}$. MS conditions were as follows: electron ionization (EI); full-scan mode $(\mathrm{m} / \mathrm{z} 35-780)$; electron energy, $70 \mathrm{eV}$ [23]. The chromatographic differences between sample groups were obvious, and the retention time was reproducible and stable, demonstrating the reliability of metabolomics analysis.

\section{Data processing and statistical analysis}

XCMS software was used to identify and quantify mass spectral peaks. Data preprocessing, including raw data filtering, peak detection, alignment, normalization, and identification, was performed automatically. Metabolites were identified by comparison of mass spectra with the National Institution of Standards and Technology (NIST), Wiley metabolome, Golm metabolome (GM), and in-house databases (Additional file 1: Table S1, red color) [24]. Six independent experiments were performed for each conclusion. Pattern recognition methods based on principal component analysis (PCA) and orthogonalpartial least squares-discriminant analysis (OPLS-DA) were then carried out using SIMCA-P V13.0 (Umetrics $A B$, Umea, Sweden). All variables were unit variance scaled before PCA and OPLS-DA. Hierarchical clustering analysis was carried out using $\mathrm{R}$ software (version 3.1.3) to visualize and group metabolite profiles. A list of variance metabolites that contributed mostly to the model was generated from the $P$ values obtained using Student's $t$ tests $(P<0.05)$ and variable importance in the projection values $(>1)$. In addition, the false discovery rate (FDR) significance criterion was performed with an FDR limit of 0.05 to avoid false-positive results in analyzing differential metabolite correlations. Metabolic pathways were constructed according to pathway analysis of the Metaboanalyst and KEGG metabolic databases [25, 26].

\section{In silico analysis of a genome-scale metabolic model}

The reconstructed genome-scale metabolic network (iZX637) of A. pullulans, containing 1347 reactions and 1133 metabolites, was used for constraint-based flux analyses [27] to determine the most effective route for maximizing PMA production and minimizing the influence of biomass accumulation. The synthesis of PMA is closely related to MA synthesis in A. pullulans. Therefore, three routes of MA synthesis, the oxidative branches of the TCA cycle, the reductive branches of the TCA cycle, and the glyoxylate shunt, were examined. In silico, constrained reactions of the oxidative branches of the TCA cycle contained oxoglutarate dehydrogenase, aconitate hydratase, fumarase, succinate dehydrogenase, and succinate-CoA ligase. Constrained reactions of the reductive branches of the TCA cycle contained malate dehydrogenase, and constrained reactions of the glyoxylate shunt contained fumarase, isocitrate lyase, and glyoxylate lyase. For in silico simulation, the reaction fluxes corresponding to one route of MA synthesis (the oxidative branches of the TCA cycle, the reductive branches of the TCA cycle, or the glyoxylate shunt) were constrained from 0 to $140 \mathrm{mmol} / \mathrm{gDW} / \mathrm{h}$ (the reaction fluxes of other two routes of MA synthesis were set to $0 \mathrm{gDW} / \mathrm{h}$ ), and the cell growth rate was constrained from 0 to $1 \mathrm{gDW} / \mathrm{h}$. The specific PMA synthesis rate was then maximized as an objective function and the substrate uptake rates for glucose in the simulation were constrained by $10 \mathrm{mmol} /$ $\mathrm{gDW} / \mathrm{h}$. The specific PMA synthesis rate at different flux values of the cell growth rate and route of MA synthesis were plotted on the $Z$-axis of the flux profile graph. In addition, because the reductive branches of the TCA cycle were assumed to be located only in the cytoplasm in silico, the flux of malate dehydrogenase located in the 
mitochondria was set to $0 \mathrm{mmol} / \mathrm{gDW} / \mathrm{h}$ in simulation of three routes. The basic tools used for the model analysis were flux balance analysis (FBA) [28]. GLPK (freeware) (http://www.gnu.org/software/glpk/) was used as a linear programming solver. The COBRA Toolbox 2.0 [29] was used for calculation and analysis in the MATLAB environment.

\section{Gene cloning and expression in the host strain}

The DNA of $A$. pullulans was extracted using a TIANamp Yeast DNA Kit (TIANGEN, China) and was used as a template to amplify the pyruvate carboxylase ( $p y c$, EC: 6.4.1.1) gene. First, one 3.748-kb pyc fragment was amplified using SmaI-pyc-S and MunI-pyc-A, as listed in Additional file 1: Table S1. Second, the pyc fragment obtained was double digested with SmaI and MunI and then ligated into plasmid pBARGPE1, which was also treated with SmaI and EcoRI (MunI isocaudarner) to generate the plasmid pBARGPE1-pyc, which contained a gpdA promoter (PgpdA) and a trpC terminator (TtrpC) flanking the $p y c$ gene. The PgpdA-pyc-TtrpC cassette was amplified by primers PgpdA.pyc.TtrpC-S and PgpdA.pyc. TtrpC-A. The PgpdA-pyc-TtrpC cassette was cloned into the EcoRI site of the pK2-PtrpC-hyg-TtrpC plasmid using a One Step Cloning Kit (Vazyme, USA), forming the plasmid pK2-hyg-pyc for A. tumefaciens-mediated transformation (ATMT), as described in our previous study [30]. T-DNA insertion sites were analyzed using a Genome Walking Kit (TaKaRa, Japan) in ATMT-derived clones. Polymerase chain reaction (PCR) primers were used to amplify the T-DNA flanking sequence (Additional file 1: Table S1).

\section{Batch and fed-batch fermentation in a 5-L stirred-tank fermentor}

Batch fermentation kinetics were studied in a 5-L stirredtank fermentor (Shanghai Baoxing Co., Ltd., China) containing $3.5 \mathrm{~L}$ of fermentation media (with glucose as carbon resource) or only diluted sugarcane molasses. The fermentation medium was inoculated with $350 \mathrm{~mL}$ of the seed culture grown in a shake flask for $48 \mathrm{~h}$ and operated at $25{ }^{\circ} \mathrm{C}$ with agitation and aeration at $400-700 \mathrm{rpm}$ and $0.8 \mathrm{vvm}$, respectively. During fermentation, the agitation was controlled to maintain the dissolved oxygen level at greater than $20 \%$. For sugarcane molasses fermentation, the crude sugarcane molasses (containing $\sim 420 \mathrm{~g} / \mathrm{kg}$ of total sugar and $14.29 \pm 0.27 \mathrm{~g} / \mathrm{kg}$ of total nitrogen) were diluted by water to $\sim 90 \mathrm{~g} / \mathrm{L}$ total sugar. For fed-batch fermentation, when the total sugar concentration was lower than $30 \mathrm{~g} / \mathrm{L}$, sugarcane molasses (approximately 270-g/L reducing sugars) was continuously added to maintain the total sugar concentration at approximately $10-20 \mathrm{~g} / \mathrm{L}$. Broth samples were collected periodically for the analysis of residual sugar, biomass, and PMA titers. All trials were performed in triplicate.

\section{Quantitative reverse transcription (RT)-PCR}

Total RNA was extracted using a Fungal RNA Kit (Omega, USA) and reverse transcribed into cDNA using reverse transcriptase (TIANGEN). The quantitative PCR assay was performed using the SYBR Green method (FastQuant RT Super Mix; TIANGEN). Primers for the pyc gene are shown in Additional file 1: Table S1. The gene encoding $\beta$-actin was used as the reference gene.

\section{Analytical methods}

Biomass was determined by the dry cell weight method. Prior to measurement, excessive $\mathrm{CaCO}_{3}$ was eliminated from the broth by adding 1-M $\mathrm{HCl}$. The cell suspension was centrifuged at $4000 \times g$ and then dried overnight at $105{ }^{\circ} \mathrm{C}$ [31]. PMA was analyzed by centrifuging the fermentation broth and the resulting supernatant was mixed with an equal volume of $2-\mathrm{M} \mathrm{H}_{2} \mathrm{SO}_{4}$ in an incubator at $85{ }^{\circ} \mathrm{C}$ for $8 \mathrm{~h}$. The hydrolyzed PMA sample was analyzed by high-performance liquid chromatography (Agilent 1260, USA) using a Spursil C18-EP organic acid column at $40{ }^{\circ} \mathrm{C}$ and eluted with $5-\mathrm{mM} \mathrm{H}_{2} \mathrm{SO}_{4}$ at a rate of $0.6 \mathrm{~mL} / \mathrm{min}$ to determine its malic acid content [32]. The glucose concentration was measured using a fully automatic residual sugar analyzer (Biology Institute of Shandong Academy of Sciences, China).

\section{Results and discussion}

Evaluation of carbon sources in shake-flask culture

Sugarcane molasses is the main by-product of sugar production, and mainly comprises sucrose and some glucose and fructose. In this study, fermentation with different carbon sources in shake-flask culture was investigated (Fig. 1). Of the carbon sources used, sucrose and fructose showed superior PMA production of $28.30 \pm 2.58$ and $22.58 \pm 1.08 \mathrm{~g} / \mathrm{L}$, respectively, which was higher than that $(20.38 \pm 2.32 \mathrm{~g} / \mathrm{L})$ from glucose as the carbon source. Moreover, five-carbon sugar (arabinose and xylose) fermentation was also superior to that with glucose for PMA production. In our previous study, a novel PMA-producing strain, A. pullulans YJ6-11, was also found to utilize xylose as a superior carbon source compared with glucose [33]. The fermentation kinetics of sucrose and glucose in shake-flask culture are shown in Fig. 2. A total of $33.91 \pm 3.70 \mathrm{~g} / \mathrm{L}$ PMA $(\sim 38.98 \mathrm{~g} / \mathrm{L} \mathrm{MA}$ after hydrolysis) were produced from $\sim 90 \mathrm{~g} / \mathrm{L}$ sucrose in $96 \mathrm{~h}$ via batch fermentation; this was increased by $40.7 \%$ compared with that of glucose $(24.10 \pm 3.30 \mathrm{~g} / \mathrm{L})$. These results showed that sucrose present in sugarcane molasses was the most suitable sugar for PMA biosynthesis. 


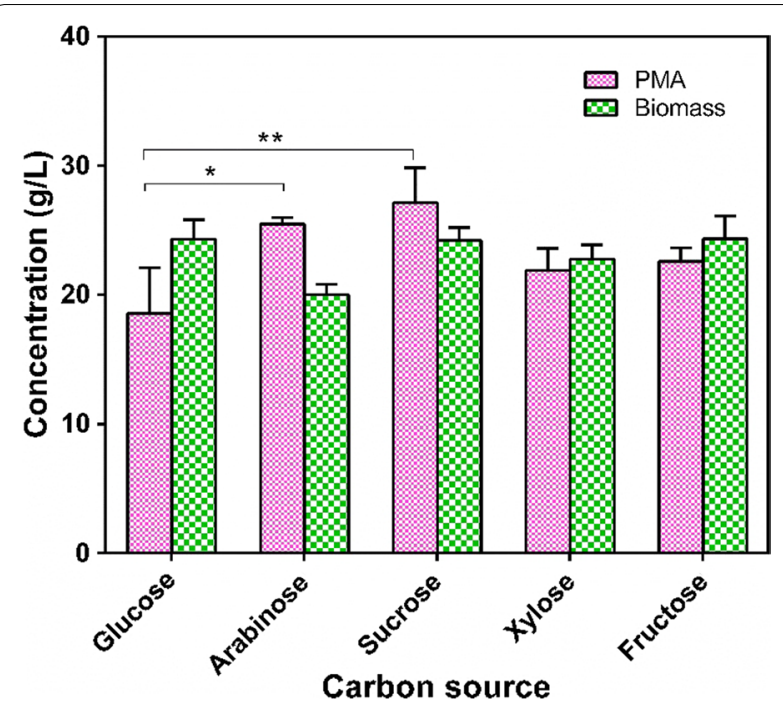

Fig. 1 Effects of carbon sources on cell growth and PMA production in shake-flask. Values are the means and standard deviations of three independent experiments. ${ }^{*} P<0.05,{ }^{* *} P<0.01$

However, the underlying factors responsible for the differences between sucrose and glucose were still unclear.

\section{Analysis of key metabolites and pathways associated with PMA biosynthesis}

To explain the differences in metabolites of $A$. pullulans, the metabolic states of sucrose- and glucose-based fermentation were compared by metabolomics analysis. As shown in Additional file 2: Table S2, in total, 81 intracellular metabolites were identified and divided into eight categories. These groups mainly included organic acids, amino acids, and sugar metabolism that contained 21, 15, and 14 metabolites, respectively. Among these metabolites, compared with culture at $48 \mathrm{~h}, 13$ and 3 differential metabolites were increased at $72 \mathrm{~h}$ in glucose and sucrose, respectively. 27 and 30 differentially abundant metabolites from glucose versus sucrose after culture for 48 and $72 \mathrm{~h}$, respectively, were validated. Of these metabolites, both at 48 and 72 h, 16 in sucrose fermentation, including fructose, ribose, glycolic acid, oleic acid, and heptanoic acid, were higher than that of glucose (Additional files 3 and 4: Figure S1 and Table S3). These results indicated that the differences of metabolites were varied in the different sugar fermentation. Moreover, compared with glucose fermentation at $48 \mathrm{~h}, 13$ differential metabolites were increased at $72 \mathrm{~h}$. Notably, at $72 \mathrm{~h}$, citric acid was increased by 1.84 -fold, whereas other intermediate metabolites associated with the TCA cycle (such as pyruvic acid, succinic acid, and fumaric acid) did not differ significantly at $48 \mathrm{~h}$ (Additional file 4: Table S3). However, at $72 \mathrm{~h}$, MA was decreased by 1.04 -fold compared
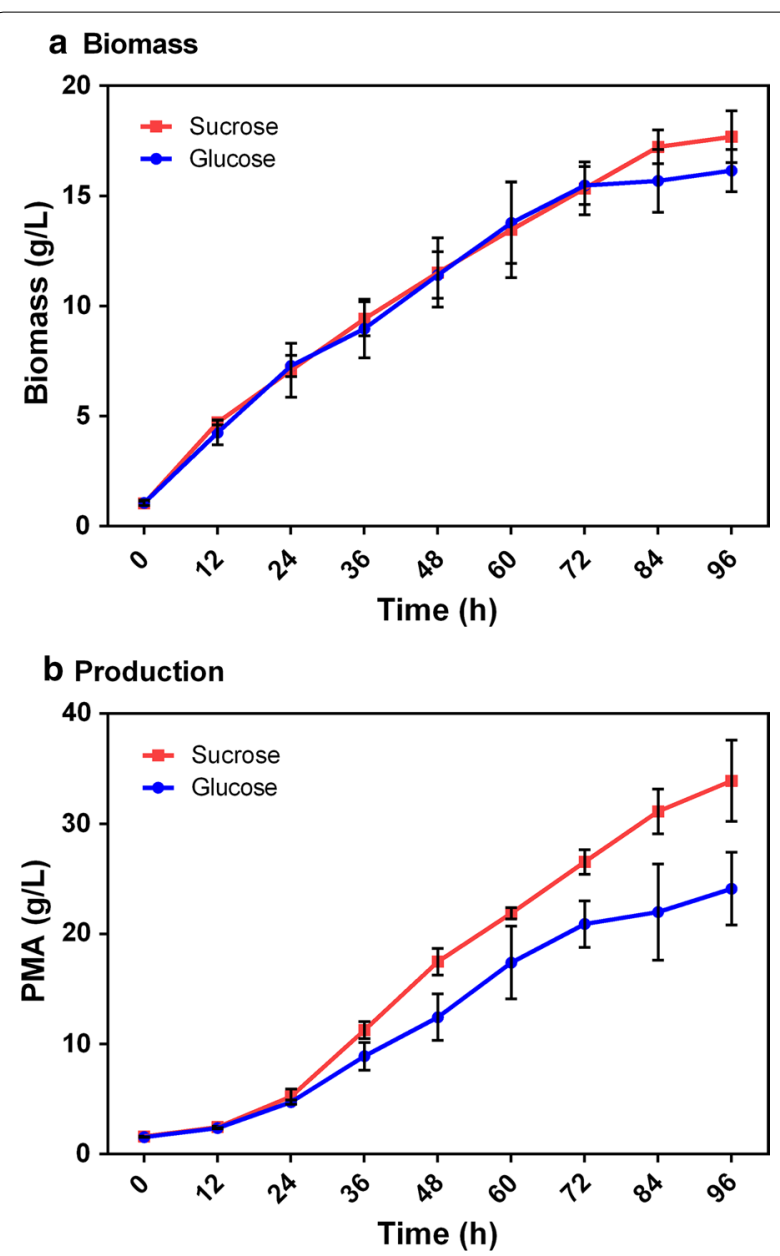

Fig. 2 Batch fermentation of PMA production from glucose or sucrose in shake-flask culture. a Biomass and $\mathbf{b}$ PMA production. Glucose: line with blue circles; sucrose: line with red squares.

The values shown represent the means of three independent experiments, and the error bars represent standard deviations of three values

with that at $48 \mathrm{~h}$, which was negative correlated with citric acid (Fig. 3). This may induce a decrease in PMA biosynthesis, because accumulation of citric acid resulted in carbon flux that was not efficiently channeled to the objective product. Pyruvate is a key node in central carbon metabolism and plays a major role in pathways related to organic acid synthesis [34]. The carbon flux can be channeled into different products through pyruvate, including succinate [35], lactate [36], and malate [37]. The reductive TCA cycle has been identified as the most efficient pathway for many products, such as succinate [38] and malate [37]. Thus, the accumulation of citric acid also indicated that metabolic flux could not effectively direct pyruvate to PMA synthesis or the highefficiency PMA synthesis route in native metabolic regulation. Therefore, the enhanced carboxylation of pyruvate 


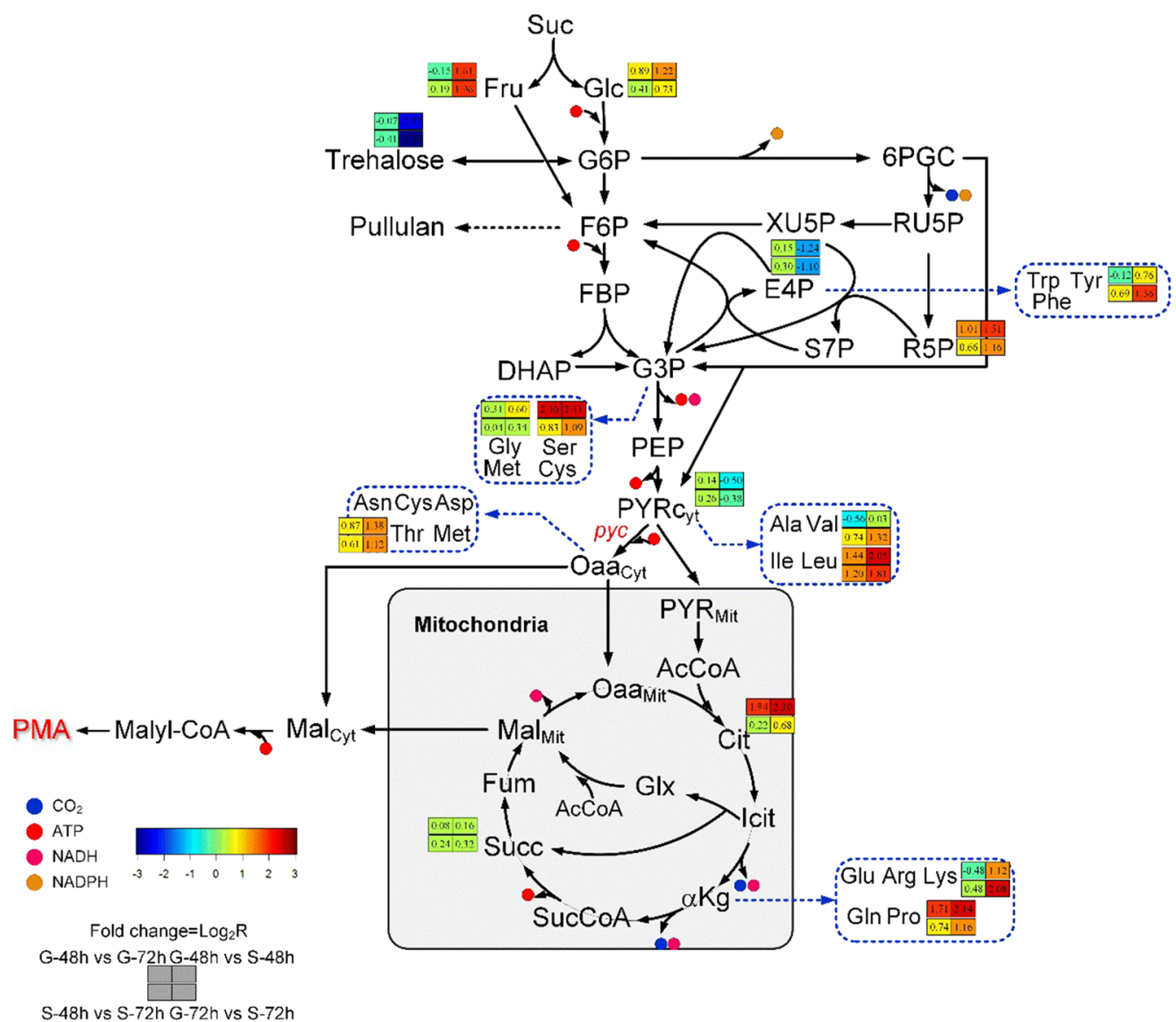

Fig. 3 Key metabolite changes in PMA biosynthesis based on comparative metabolome analysis. Suc sucrose, G/c glucose, Fru fructose, G6P glucose 6-phosphate, F6P fructose-6-phosphate, FBP fructose 1,6-bisphosphate, DHAP dihydroxyacetone phosphate, G3P glyceraldehyde 3-phosphate, 6PGC gluconate 6-phosphate, RU5P ribulose 5-phosphate, XU5P xylulose 5-phosphate, R5P ribose 5-phosphate, E4P erythrose 4-phosphate, S7P sedoheptulose 7-phosphate, PEP phosphoenolpyruvate, PYR pyruvate, OAA oxaloacetic acid, AcCoA acetyl-CoA, Cit citrate, lcit isocitrate, aKg a-oxoglutarate, SucCoA succinyl-CoaA, Succ succinate, Fum fumarate, Mal malate, Glx glyoxylate, Trp tryptophan, Tyr tyrosine, Phe phenylalanine, Gly glycine, Ser serine, Met methionine, Cys cysteine, Asn asparagine, Asp aspartic acid, Thr threonine, Ala alanine, Val valine, Ile isoleucine, Leu leucine, Glu glutamic acid, Arg arginine, Lys lysine, Gln glutamine, Pro proline. The content of metabolites in A. pullulans CTCC2012223 cultured in glucose for $48 \mathrm{~h}$ was used as control and defined as 1.00; the contents of the other samples were used to calculate the fold change with the following formula: fold change $=\log _{2}(R), R=B / A, A$ is the control, and $B$ is the treated sample

to oxaloacetate, catalyzed by pyruvate carboxylase, may be an important target for improving PMA synthesis.

In addition, pyruvate is also a major component in pathways related to amino acid metabolism. Amino acids are crucial to microorganism metabolism and have roles in synthesis of proteins (e.g., leucine, threonine, and phenylalanine), regulation of gene expression (e.g., arginine and leucine), osmoregulation (e.g., citrulline and proline), control of enzyme activity (e.g., alanine and leucine), transamination (e.g., aspartate, alanine, and glutamate), and ammonia detoxification (e.g., citrulline, arginine, and glutamate) [39]. As shown in Fig. 3, amino acids present at higher levels, particularly leucine and proline, could be directly or indirectly transformed from pyruvate and $\alpha$-oxoglutarate [40]. Most amino acids were observed at higher levels in sucrose than in glucose because of the abundant precursors in the glycolytic pathway and TCA cycle. The redox balance is maintained by modifying the distribution of the metabolic flux of pyruvate [41].

In addition, when sucrose was used as the carbon source, relative concentration of trehalose was significantly decreased 2.37- and 2.70-fold at 48 and $72 \mathrm{~h}$, respectively, compared with that when glucose was used as the carbon source (Additional file 4: Table S3). Accumulation of trehalose in yeasts has been shown to be an important mechanism mediating tolerance against adverse stress conditions, and trehalose functions as a reserve carbohydrate that can be synthesized when the exogenous energy exceeds the cellular needs for growth and biosynthesis $[42,43]$. These results suggested that 
glucose as a rapidly metabolizable carbon source can induce a regulatory response (e.g., osmotic stress) to restore excess exogenous energy, which would cause some of the carbon source to be used for other processes, not PMA synthesis, thereby decreasing PMA titers.

\section{In silico analysis of a genome-scale metabolic model}

PMA is synthesized from MA, which is an intermediate in the TCA cycle in aerobic metabolism. Genome-scale flux sensitivity analyses were performed to determine the most effective route for maximizing PMA synthesis. Three metabolic routes involved in MA synthesis, including oxidative branches of the TCA cycle, reductive branches of the TCA cycle, and glyoxylate shunt, were simulated using the genome-scale metabolic model (iZX637). As shown in Fig. 4, the optimal PMA synthesis rate, using glucose or sucrose as the carbon source, reached $15 \mathrm{mmol} / \mathrm{gDW} / \mathrm{h}$ (indicated by an arrow), increasing the reductive TCA malate synthesis rate to $15 \mathrm{mmol} / \mathrm{gDW} / \mathrm{h}$ and the biomass growth rate to $0 \mathrm{mmol} / \mathrm{gDW} / \mathrm{h}$. When the carbon flux turned to oxidative branches of the TCA cycle and the glyoxylate shunt, the optimal PMA synthesis rates reached only as high as $12.89 \mathrm{mmol} / \mathrm{gDW} / \mathrm{h}$ (sucrose as a carbon source:
$12.58 \mathrm{mmol} / \mathrm{gDW} / \mathrm{h}$ ) and $14.67 \mathrm{mmol} / \mathrm{gDW} / \mathrm{h}$ (sucrose as a carbon source: $14.33 \mathrm{mmol} / \mathrm{gDW} / \mathrm{h}$ ) with corresponding malate synthesis rates of 13 and $8 \mathrm{mmol} / \mathrm{gD} / \mathrm{h}$, respectively. In addition, the malate synthesis rate of the corresponding route constantly increased, resulting in a negative influence on the optimal PMA synthesis rate. When the malate synthesis rates of the reductive TCA route, oxidative TCA route, and glyoxylate shunt reached 120,37 , and $37 \mathrm{mmol} / \mathrm{gDW} / \mathrm{h}$, respectively, the PMA synthesis rate and biomass growth rate were reduced to $0 \mathrm{mmol} / \mathrm{gDW} / \mathrm{h}$ (glucose or sucrose as a carbon source). Furthermore, the PMA synthesis rate decreased gradually as the biomass synthesis rate increased for all simulation results. These results showed that PMA and biomass synthesis showed a competitive relationship. However, in the reductive TCA route, biomass synthesis could be maintained with a relatively high PMA synthesis rate compared with the other two routes, regardless of whether glucose or sucrose was used as the carbon source. In our previous study, we found that high levels of the nitrogen source favored cell growth but decreased PMA synthesis [44]. Therefore, the efficiency of the PMA synthesis route should balance cell growth and PMA formation. In our previous study, in silico analysis of the

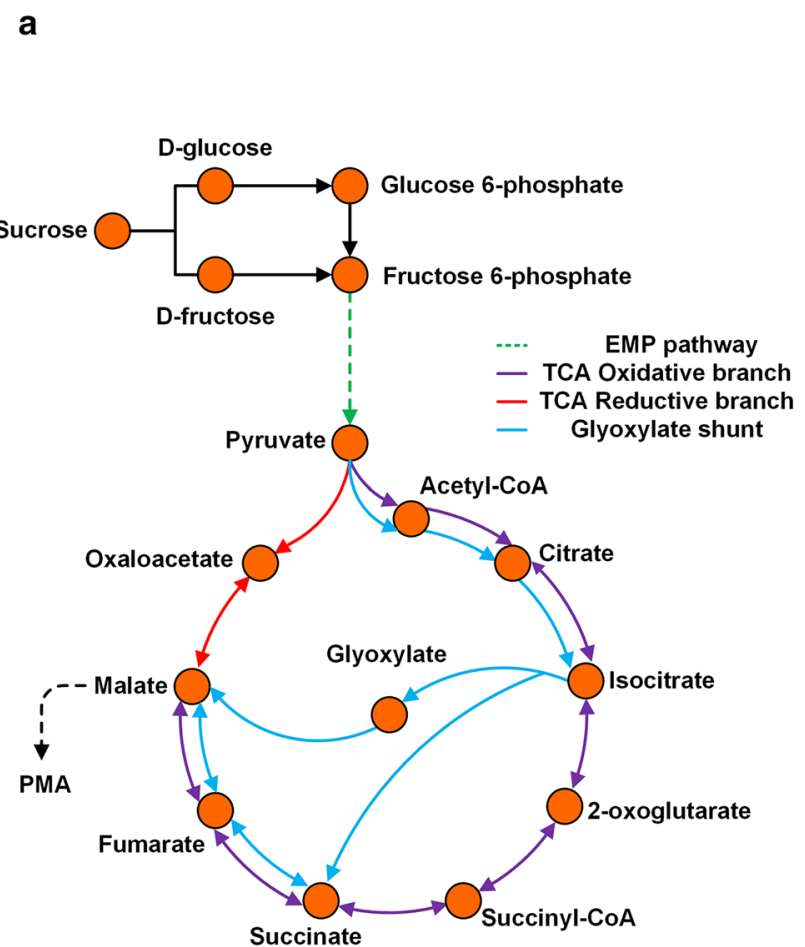

b
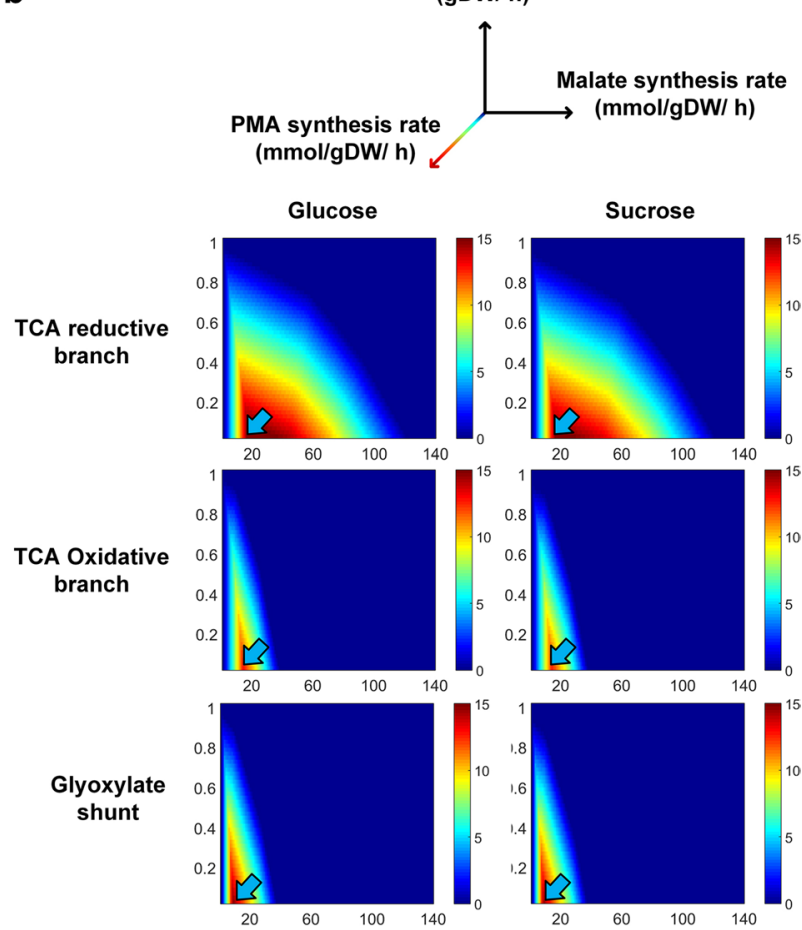

Fig. 4 Evaluation of malate synthesis route for PMA production based on genome-scale metabolic simulation. a Schematic of simulation analysis in different malate synthesis route. $\mathbf{b} X$ - and $Y$-axes show malate synthesis route flux ( $\mathrm{mmol} / \mathrm{gDW} / \mathrm{h})$ and PMA production rate $(\mathrm{mmol} / \mathrm{gDW} / \mathrm{h})$, respectively. The $Z$-axis represents the cell growth rate $(\mathrm{gDW} / \mathrm{h})$. The color gradient represents the value according to the scale shown in the box 
carbon flux distribution and changes in PMA synthesis rates showed that, in the context of a high PMA synthesis rate, a large amount of carbon flux was transformed into pyruvate and channeled into the reductive TCA route by pyruvate carboxylase [27]. These in silico results showed that the reductive TCA route, as the optimal PMA synthesis route, showed a relatively high optimal PMA synthesis rate and mitigated the competitive relationship between PMA and biomass synthesis. In addition, the simulation results also showed that the reductive TCA route required a relatively high route flux (the reductive TCA malate synthesis rate to $15 \mathrm{mmol} / \mathrm{gDW} / \mathrm{h}$ ), yielding a high PMA synthesis rate (the optimal PMA synthesis rate to $15 \mathrm{mmol} / \mathrm{gDW} / \mathrm{h}$ ). Therefore, pyruvate carboxylase $(p y c)$ in the reductive TCA route was selected as the target to be overexpressed to improve PMA yield and productivity.

Moreover, according to the simulation result from sucrose and glucose as carbon sources, sucrose was not dominant compared with glucose as a carbon source for the optimal PMA synthesis rate and cell growth by $A$. pullulans strains in the conversion efficiency of metabolic pathways. This could be explained by the observations that the reaction of sucrose hydrolysis exhibited no energy consumption or carbon loss in silico.

\section{Overexpression of the pyc gene in A. pullulans}

To evaluate the effects of the $p y c$ gene on PMA biosynthesis, the endogenous $p y c$ gene was amplified using the genomic DNA of A. pullulans as a template (Additional file 3: Figure S2). The PgpdA promoter of Aspergillus nidulans, which directs the constitutively high expression of the glyceraldehyde-3-phosphate dehydrogenase $(g p d)$ gene, can be used to induce high levels of constitutive expression of genes of interest or marker genes and to drive the overexpression of various genes in fungi [45-47]. Therefore, the PgpdA promoter of A. nidulans was used to constitute the $p y c$ cassette by cloning into pBARGPE1 (Additional file 3: Figure S3). In our previous study, we developed a simple and efficient system for genetic transformation of $A$. pullulans using $A$. tumefaciens [30]. Therefore, A. tumefaciens carrying the pK2-hyg-pyc binary plasmid was used to transform $A$. pullulans. Because ATMT-mediated integration is random, five different ATMT-derived clones were tested for PMA production in shake-flask culture. The PMA titers of five clones compared with the wild-type strain were improved from 3.5 to $7.1 \%$ (Additional file 3: Figure S4). The differences among mutants were due to random integration, causing interruption of gene function by insertion of T-DNA, and were not caused by intrinsic factors [30]. This result indicated that the increased PMA titer was mainly dependent on $p y c$ gene overexpression. Thus, we selected the highest PMA producer (E10 strain; as called FJ-PYC) for further analysis of the sequences flanking the T-DNA in the genome. As shown in Additional file 3: Figure S5, the hygromycin B resistance cassette and overexpression pyc cassette were inserted into the noncoding regions of g4940.t1 and g4941.t1 on the A. pullulans genome. The insertions did not disrupt the g4940. t1 and g4941.t1 open reading frames. Furthermore, we found that the expression level of the $p y c$ gene in strain E-10 was increased by 9.5 -fold compared with that in the wild-type strain (Fig. 5). These results also revealed that the promoter PgpdA was an effective tool for regulating gene expression in A. pullulans.

Subsequently, the engineered strain E10 was tested with glucose as the carbon source in a 5-L stirred-tank fermentor. As shown in Fig. 6, about $36.2 \mathrm{~g} / \mathrm{L}$ of PMA was produced via batch fermentation, with a PMA productivity of $0.53 \mathrm{~g} / \mathrm{L} \mathrm{h}$, which was increased by 15.1 and $12.7 \%$ compared with the control, respectively. This result indicated that overexpression of the $p y c$ gene could improve the production of PMA, which was consistent with the results of in silico simulation showing that strengthening of the reductive TCA route resulted in increased carbon flux toward PMA synthesis.

\section{Batch and fed-batch fermentation with sugarcane molasses}

Sugarcane molasses is a low-cost by-product of sugar production and mainly contains sucrose, with some fructose and glucose. To develop an economical fermentation process, sugarcane molasses without any pretreatment or nutrient supplementation was employed for PMA production by FJ-PYC strain in a 5-L stirred-tank fermentor. As shown in Fig. 7a, during the early fermentation stage, sucrose was rapidly consumed and transformed into glucose and fructose, and glucose was then used for cell

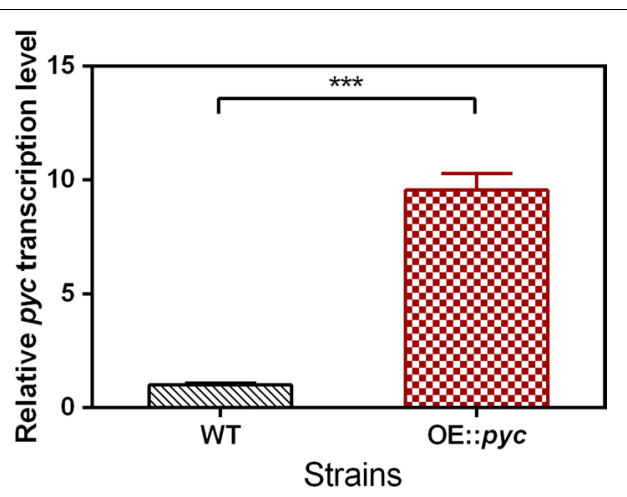

Fig. 5 Expression level of the pyc gene in the engineered strain E10. Each column was calculated with three parallel experiments. ${ }^{* * *} P<0.001$ versus the wild-type strain 


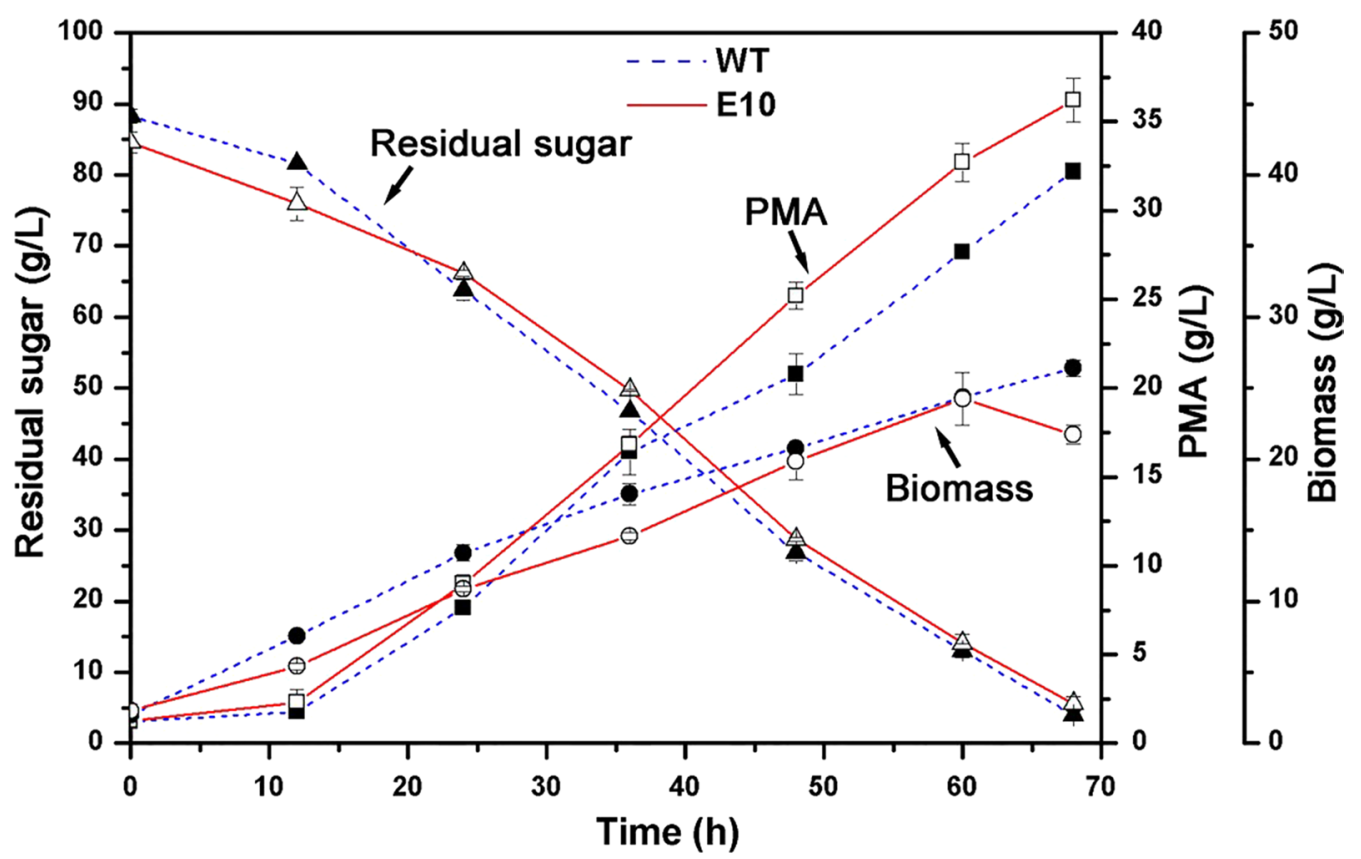

Fig. 6 Batch fermentation of PMA production with the engineered strain E10 in a stirred-tank fermentor. All the data were derived from two independent experiments

growth and PMA synthesis compared with fructose. This phenomenon, called glucose-mediated carbon catabolite repression $(\mathrm{CCR})$, is widely observed in bacteria and yeasts [48-50]. About 31.5-g/L PMA (36.5-g/L MA after hydrolysis) was produced from $\sim 95-\mathrm{g} / \mathrm{L}$ mixed sugar (61.8-g/L sucrose, 18.5-g/L glucose, and 15.3-g/L fructose from sugarcane molasses) in $60 \mathrm{~h}$ via batch fermentation, with an MA yield of $0.44 \mathrm{~g} / \mathrm{g}$. Moreover, without adding any other media, the productivity of PMA $(0.53 \mathrm{~g} / \mathrm{L} \mathrm{h})$ was the same as that from glucose fermentation. In fedbatch fermentation (Fig. 7b), a high final PMA titer of $81.5 \mathrm{~g} / \mathrm{L}$ (94.2-g/L MA after hydrolysis) was achieved in $140 \mathrm{~h}$ with a corresponding MA yield of $0.62 \mathrm{~g} / \mathrm{g}$ and productivity of $0.67 \mathrm{~g} / \mathrm{L} \mathrm{h}$. As shown in Table 1 , compared with other renewable feedstocks, PMA fermentation from sugarcane molasses by strain FJ-PYC resulted in the highest titer and productivity. Nevertheless, the titer and productivity could be further increased by continuous fed operation, because the PMA synthesis rate maintained a high speed. In addition, the fed-batch fermentation with FJ-PYC resulted in an overall MA yield of $0.62 \mathrm{~g} / \mathrm{g}$ from sugarcane molasses without nitrogen supplementation, which was the same as the highest yield from sugarcane juice [49]. However, sugarcane juice contained only $\sim 15 \%$ reducing sugars and relatively fewer inhibitors, requiring it to be condensed for high-sugar PMA fermentation and dramatically decreasing its economic efficiency. These results indicated that the strain
FJ-PYC exhibited extremely high adaptation and tolerance against sugarcane molasses.

\section{Conclusions}

In this study, different carbon sources were evaluated, and sugarcane molasses was assessed as a potential feedstock for economic PMA and MA production. Among the different carbon sources examined in this study, sucrose was found to be the optimal carbon source for PMA biosynthesis. Metabolomics analysis of sucroseand glucose-based fermentation identified a total of 81 intracellular metabolites and showed that pyruvate from the glycolysis pathway may be a key metabolite affecting PMA synthesis. In silico analysis of a genome-scale metabolic model (iZX637) verified that the pyc gene via the reductive TCA cycle was a target affecting PMA synthesis. Consistent with this, overexpression of the pyc gene in A. pullulans strain FJ-PYC increased the PMA titer by $15.1 \%$ compared with the control.

Moreover, sugarcane molasses could be directly utilized by this recombinant strain without any pretreatment or nutrient supplementation, producing $31.5-\mathrm{g} / \mathrm{L}$ PMA (36.5-g/L MA) with a high-level PMA productivity of $0.53 \mathrm{~g} / \mathrm{L} \mathrm{h}$ in batch fermentation. In fed-batch fermentation, compared with the other renewable feedstock, the highest final PMA titer of $81.5 \mathrm{~g} / \mathrm{L}$ (94.2-g/L MA after hydrolysis) was achieved in $140 \mathrm{~h}$, with a corresponding MA yield of $0.62 \mathrm{~g} / \mathrm{g}$ and productivity of $0.67 \mathrm{~g} / \mathrm{L} \mathrm{h}$. 

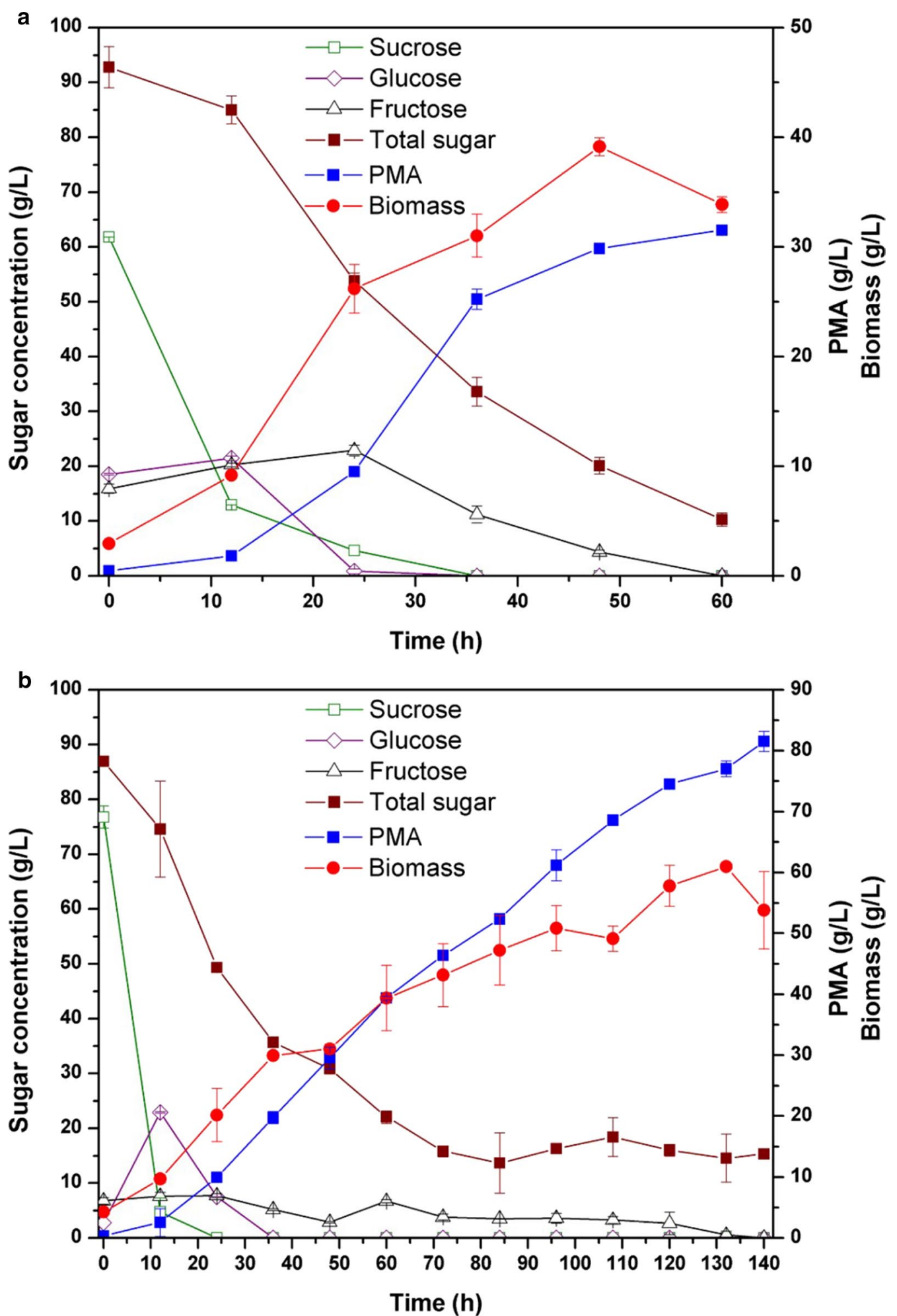

Fig. 7 Fermentation kinetics of PMA production from sugarcane molasses in a stirred-tank fermentor. a Batch fermentation; $\mathbf{b}$ fed-batch fermentation. PMA production is reported as malic acid content after acid hydrolysis of PMA. All the data were derived from two independent experiments 
Table 1 PMA production from various biomass substrates by different strains of $A$. pullulans

\begin{tabular}{|c|c|c|c|c|c|c|c|c|}
\hline Microorganism & Substrates & $\begin{array}{l}\text { Nitrogen } \\
\text { sources }\end{array}$ & $\begin{array}{l}\text { Operating } \\
\text { mode }\end{array}$ & $\mathrm{PMA}^{\mathrm{a}}(\mathrm{g} / \mathrm{L})$ & Malic acid (g/L) & $\begin{array}{l}\text { Productivity }^{a} \\
\text { (g/L h) }\end{array}$ & Yield $^{a}(g / g)$ & References \\
\hline \multirow[t]{2}{*}{ NRRL 50383} & Corn fiber & $\begin{array}{l}\text { Peptone and } \\
\text { yeast extract }\end{array}$ & Batch & 10.1 & $11.7^{b}$ & 0.07 & - & [13] \\
\hline & Wheat straw & $\begin{array}{l}\text { Peptone and } \\
\text { yeast extract }\end{array}$ & Batch & 23.5 & $27.1^{\mathrm{b}}$ & 0.16 & - & \\
\hline \multirow[t]{3}{*}{$Z X-10$} & $\begin{array}{l}\text { Soybean hull } \\
\text { hydrolysate }\end{array}$ & $\begin{array}{l}\text { Corn steep } \\
\text { liquor }\end{array}$ & Fed-batch & 27.2 & 31.3 & 0.48 & 0.42 & [12] \\
\hline & Soy molasses & - & Fed-batch & 62.6 & 71.9 & 0.29 & 0.69 & \\
\hline & Sugarcane juice & - & Batch & 52.6 & 60.8 & 0.32 & 0.62 & [49] \\
\hline \multirow[t]{2}{*}{ СCTCCM2012223 } & $\begin{array}{l}\text { Hydrolysate of } \\
\text { raw sweet } \\
\text { potato }\end{array}$ & $\mathrm{NH}_{4} \mathrm{NO}_{3}$ & Batch & 29.6 & 33.6 & 0.28 & 0.31 & [9] \\
\hline & $\begin{array}{l}\text { Hydrolysate of } \\
\text { raw sweet } \\
\text { potato }\end{array}$ & $\mathrm{NH}_{4} \mathrm{NO}_{3}$ & Fed-batch & 44 & 49.9 & 0.31 & 0.22 & \\
\hline YJ 6-11 & $\begin{array}{l}\text { Corncob hydro- } \\
\text { lysate }\end{array}$ & $\mathrm{NH}_{4} \mathrm{NO}_{3}$ & Batch & 28.6 & 32.4 & 0.45 & 0.41 & [33] \\
\hline \multirow[t]{2}{*}{ FJ-PYC } & \multirow{2}{*}{$\begin{array}{c}\text { Sugarcane } \\
\text { molasses }\end{array}$} & - & Batch & 31.5 & 36.5 & 0.61 & 0.44 & This study \\
\hline & & - & Fed-batch & 81.5 & 94.2 & 0.67 & 0.62 & \\
\hline
\end{tabular}

- , none or not reported

a To facilitate comparisons, PMA yield and productivity were based on the malic acid that can be released from PMA after hydrolysis, PMA ( $\mathrm{g} / \mathrm{L}$ ) $=0.87 \mathrm{malic}$ acid $(\mathrm{g} / \mathrm{L}$ )

b Calculated from data in this study

This study demonstrated the great potential of sugarcane molasses for the economical production of PMA and MA on the industrial scale.

\section{Additional files}

\section{Additional file 1: Table S1. List of strains, plasmids, and primers.}

Additional file 2: Table S2. Identified metabolites by comparison of mass spectra.

Additional file 3: Figure S1. The statistical numbers of differential metabolites between groups. Red bars represent the numbers of relative concentration increased metabolites and blue bars represent the numbers of relative concentration decreased metabolites. Figure S2. PCR amplification of the endogenous pyc gene using the genomic DNA of A. pullulans. Figure S3. Construction of the pyc cassette by cloning into the plasmid PBARGPE1 with the PgpdA promoter. Figure S4. Batch fermentation of different ATMT-derived clones with glucose as carbon source in shake flask. Figure $\mathbf{S 5}$. Analysis of sequences flanking to T-DNA in genome of the strain E10.

Additional file 4: Table S3. The changes of differential metabolites in glucose- and sucrose-based fermentation.

\section{Abbreviations}

PMA: polymalic acid; MA: L-malic acid; pyc: pyruvate carboxylase gene; TCA : tricarboxylicacid; GEM: genome scale metabolic model; HPLC: high-performance liquid chromatography; BSTFA: bis(trimethylsilyl) trifluoroacetamide; GC-MS: gas chromatography-mass spectrometry; El: electron ionization; NIST: National Institution of Standards and Technology; GM: Golm Metabolome; PCA: principal component analysis; OPLS-DA: orthogonal-partial least squaresdiscriminant analysis; FDR: false discovery rate; PgpdA: gpdA promoter; TtrpC: trpC terminator; ATMT: A. tumefaciens-mediated transformation; PCR: polymerase chain reaction; gpd: glyceraldehyde-3-phosphate dehydrogenase gene; CCR: carbon catabolite repression.

\section{Authors' contributions}

FJ and ZX designed and carried out the model simulations and fermentations. YJ and JC evaluated effects of carbon sources on cell growth and PMA production different carbon sources and analyzed the data of metabolome. FJ and YJ drafted the manuscript. YWW assisted in shake-flask fermentation. ZX and MJ supervised the project and revised the manuscript. All authors read and approved the final manuscript.

\section{Author details}

${ }^{1}$ College of Pharmaceutical Sciences, Chongqing Engineering Research Center for Pharmaceutical Process and Quality Control, Southwest University, 2 Tian Sheng Road, Beibei, Chongqing 400715, People's Republic of China.

${ }^{2}$ Wuhan Sunhy Biology Co., Ltd, Wuhan 430074, People's Republic of China. ${ }^{3}$ School of Chemical Engineering \& Pharmacy, Wuhan Institute of Technology, Wuhan 430205, People's Republic of China. ${ }^{4}$ State Key Laboratory of Materials-Oriented Chemical Engineering, College of Biotechnology and Pharmaceutical Engineering, Nanjing Tech University, Nanjing 211816, People's Republic of China.

\section{Acknowledgements}

This study was supported in part by Grants from the National Natural Science Foundation of China (Grant No. 31571816), National High Technology Research and Development Program of China (863 Program) (2015AA021005), Chongqing Social and People's Livelihood Guarantee Special Program (cstc2016shmszx80075), and State Key Laboratory of Materials-Oriented Chemical Engineering (Nanjing Tech University), China (KL15-10).

\section{Competing interests}

The authors declare that they have no competing interests.

\section{Availability of supporting data}

The GEM iZX637 during the current study is available in the PubMed repository https://doi.org/10.1016/j.gene.2016.12.034.The authors declare that all 
other data supporting the findings of this study are available within the article its Additional files.

\section{Consent for publication}

The authors consent for publication.

\section{Ethics approval and consent to participate}

Not applicable.

\section{Publisher's Note}

Springer Nature remains neutral with regard to jurisdictional claims in published maps and institutional affiliations.

\section{Received: 28 October 2017 Accepted: 26 March 2018}

Published online: 04 April 2018

\section{References}

1. Chi Z, Liu GL, Liu CG, Chi ZM. Poly(beta-L-malic acid) (PMLA) from Aureobasidium spp. and its current proceedings. Appl Microbiol Biotechnol. 2016:100:3841-51.

2. Yang YT, Lee SJ, Nai YS, Kim S, Kim JS. Up-regulation of carbon metabolism-related glyoxylate cycle and toxin production in Beauveria bassiana JEF-007 during infection of bean bug, Riptortus pedestris (Hemiptera: Alydidae). Fungal Biol. 2016;120:1236-48.

3. Zhou Q, Yang T, Qiao Y, Guo S, Zhu L, Wu H. Preparation of poly(beta-Lmalic acid)-based charge-conversional nanoconjugates for tumorspecific uptake and cellular delivery. Int J Nanomed. 2015;10:1941-52.

4. Lanz-Landazuri A, Portilla-Arias J, Martinez de Ilarduya A, Garcia-Alvarez M, Holler E, Ljubimova J, Munoz-Guerra S. Nanoparticles of esterified polymalic acid for controlled anticancer drug release. Macromol Biosci. 2014;14:1325-36.

5. Loyer P, Cammas-Marion S. Natural and synthetic poly(malic acid)based derivates: a family of versatile biopolymers for the design of drug nanocarriers. J Drug Target. 2014;22:556-75.

6. Patil R, Gangalum PR, Wagner S, Portilla-Arias J, Ding H, Rekechenetskiy A, Konda B, Inoue S, Black KL, Ljubimova JY, Holler E. Curcumin targeted, polymalic acid-based mri contrast agent for the detection of a plaques in alzheimer's disease. Macromol Biosci. 2015;15:1212-7.

7. Goldberg I, Rokem JS, Pines O. Organic acids: old metabolites, new themes. Chem Technol Biotechnol. 2006:81:1601-11.

8. Alonso S, Rendueles M, Diaz M. Microbial production of specialty organic acids from renewable and waste materials. Crit Rev Biotechnol. 2015;35:497-513.

9. Zan Z, Zou X. Efficient production of polymalic acid from raw sweet potato hydrolysate with immobilized cells of Aureobasidium pullulans CCTCC M2012223 in aerobic fibrous bed bioreactor. J Chem Technol Biotechnol. 2013;88:1822-7.

10. Wang J, Li L, Niu X, Zou D. Phosphine-induced phosphorus mobilization in the rhizosphere of rice seedlings. J Soils Sediments. 2016;16:1735-44

11. Zou X, Wang Y, Tu G, Zan Z, Wu X. Adaptation and transcriptome analysis of Aureobasidium pullulans in corncob hydrolysate for increased inhibitor tolerance to malic acid production. PLOS ONE. 2015:10:e0121416.

12. Cheng C, Zhou Y, Lin M, Wei P, Yang S-T. Polymalic acid fermentation by Aureobasidium pullulans for malic acid production from soybean hull and soy molasses: fermentation kinetics and economic analysis. Bioresour Technol. 2017:223:166-74.

13. Leathers TD, Manitchotpisit P. Production of poly(beta-L-malic acid) (PMA) from agricultural biomass substrates by Aureobasidium pullulans. Biotechnol Lett. 2013;35:83-9.

14. Chan $S$, Kanchanatawee $S$, Jantama K. Production of succinic acid from sucrose and sugarcane molasses by metabolically engineered Escherichia coli. Bioresour Technol. 2012;103:329-36.

15. Jung MY, Park BS, Lee J, Oh MK. Engineered Enterobacter aerogenes for efficient utilization of sugarcane molasses in 2,3-butanediol production. Bioresour Technol. 2013:139:21-7.
16. Putri SP, Nakayama Y, Matsuda F, Uchikata T, Kobayashi S, Matsubara A, Fukusaki E. Current metabolomics: practical applications. J Biosci Bioeng. 2013:115:579-89.

17. Teul J, Ruperez FJ, Garcia A, Vaysse J, Balayssac S, Gilard V, Malet-Martino M, Martin-Ventura JL, Blanco-Colio LM, Tunon J, et al. Improving metabolite knowledge in stable atherosclerosis patients by association and correlation of GC-MS and H-1 NMR fingerprints. J Proteome Res. 2009:8:5580-9.

18. Villas-Boas SG, Akesson M, Nielsen J. Biosynthesis of glyoxylate from glycine in Saccharomyces cerevisiae. FEMS Yeast Res. 2005;5:703-9.

19. Bugrim A, Nikolskaya T, Nikolsky Y. Early prediction of drug metabolism and toxicity: systems biology approach and modeling. Drug Discov Today. 2004;9:127-35.

20. Kim JK, Bamba T, Harada K, Fukusaki E, Kobayashi A. Time-course metabolic profiling in Arabidopsis thaliana cell cultures after salt stress treatment. J Exp Bot. 2007:58:415-24.

21. Mitsunaga H, Meissner L, Palmen T, Bamba T, Buechs J, Fukusaki E. Metabolome analysis reveals the effect of carbon catabolite control on the poly(gamma-glutamic acid) biosynthesis of Bacillus licheniformis ATCC 9945. J Biosci Bioeng. 2016;121:413-9.

22. Vanholme R, Storme V, Vanholme B, Sundin L, Christensen JH, Goeminne G, Halpin C, Rohde A, Morreel K, Boerjan W. A systems biology view of responses to lignin biosynthesis perturbations in Arabidopsis. Plant Cell. 2012;24:3506-29.

23. Wu Q, Zhang L, Xia H, Yu C, Dou K, Li Y, Chen J. Omics for understanding synergistic action of validamycin $A$ and Trichoderma asperellum GDFS1009 against maize sheath blight pathogen. Sci Rep. 2017;7:40140.

24. Smith CA, Want EJ, O'Maille G, Abagyan R, Siuzdak G. XCMS: processing mass spectrometry data for metabolite profiling using Nonlinear peak alignment, matching, and identification. Anal Chem. 2006;78:779-87.

25. Kanehisa M, Araki M, Goto S, Hattori M, Hirakawa M, Itoh M, Katayama T, Kawashima S, Okuda S, Tokimatsu T, Yamanishi Y. KEGG for linking genomes to life and the environment. Nucleic Acids Res. 2008;36:D480-4.

26. Kopka J, Schauer N, Krueger S, Birkemeyer C, Usadel B, Bergmuller E, Dormann P, Weckwerth W, Gibon Y, Stitt M, et al. GMD@CSB.DB: the Golm metabolome database. Bioinformatics. 2005;21:1635-8.

27. Feng J, Yang J, Li X, Guo M, Wang B, Yang ST, Zou X. Reconstruction of a genome-scale metabolic model and in silico analysis of the polymalic acid producer Aureobasidium pullulans CCTCC M2012223. Gene. 2017:607:1-8.

28. Orth JD, Thiele I, Palsson BO. What is flux balance analysis? Nat Biotechnol. 2010:28:245-8

29. Schellenberger J, Que R, Fleming RM, Thiele I, Orth JD, Feist AM, Zielinski DC, Bordbar A, Lewis NE, Rahmanian S, et al. Quantitative prediction of cellular metabolism with constraint-based models: the COBRA toolbox v2.0. Nat Protoc. 2011;6:1290-307.

30. Tu G, Wang Y, Feng J, Li X, Guo M, Zou X. Agrobacterium tumefaciensmediated transformation of Aureobasidium pullulans and high-efficient screening for polymalic acid producing strain. Chin J Biotechnol. 2015;31:1063-72.

31. Zou X, Zhou YP, Yang ST. Production of polymalic acid and malic acid by Aureobasidium pullulans fermentation and acid hydrolysis. Biotechnol Bioeng. 2013;110:2105-13.

32. Zou X, Tu GW, Zan ZQ. Cofactor and $\mathrm{CO}_{2}$ donor regulation involved in reductive routes for polymalic acid production by Aureobasidium pulIulans CCTCC M2012223. Bioprocess Biosyst Eng. 2014;37:2131-6.

33. Zou X, Yang J, Tian X, Guo M, Li Z, Li Y. Production of polymalic acid and malic acid from xylose and corncob hydrolysate by a novel Aureobasidium pullulans YJ 6-11 strain. Process Biochem. 2016;51:16-23.

34. Yin $X, L i J$, Shin H-d DuG, Liu L, Chen J. Metabolic engineering in the biotechnological production of organic acids in the tricarboxylic acid cycle of microorganisms: advances and prospects. Biotechnol Adv. 2015;33:830-41.

35. Gokarn RR, Evans JD, Walker JR, Martin SA, Eitemann MA, Altman E. The physiological effects and metabolic alterations caused by the expression of Rhizobium etli pyruvate carboxylase in Escherichia coli. Appl Microbiol Biotechnol. 2001;56:188-95.

36. Su Y, Rhee MS, Ingram LO, Shanmugam KT. Physiological and fermentation properties of Bacillus coagulans and a mutant lacking fermentative lactate dehydrogenase activity. J Ind Microbiol Biotechnol. 2011:38:441-50. 
37. Zelle RM, de Hulster E, van Winden WA, de Waard P, Dijkema C, Winkler AA, Geertman JMA, van Dijken JP, Pronk JT, van Maris AJA. Malic acid production by Saccharomyces cerevisiae: engineering of pyruvate carboxylation, oxaloacetate reduction, and malate export. Appl Environ Microbiol. 2008;74:2766-77.

38. Sanchez AM, Bennett GN, San KY. Efficient succinic acid production from glucose through overexpression of pyruvate carboxylase in an Escherichia coli alcohol dehydrogenase and lactate dehydrogenase mutant. Biotechnol Prog. 2005;21:358-65.

39. Wu G. Amino acids: metabolism, functions, and nutrition. Amino Acids. 2009;37:1-17

40. Xia M, Huang D, Li S, Wen J, Jia X, Chen Y. Enhanced FK506 production in Streptomyces tsukubaensis by rational feeding strategies based on comparative metabolic profiling analysis. Biotechnol Bioeng. 2013;110:2717-30.

41. Thierry A, Deutsch S-M, Falentin H, Dalmasso M, Cousin FJ, Jan G. New insights into physiology and metabolism of Propionibacterium freudenreichii. Int J Food Microbiol. 2011;149:19-27.

42. Jiang H, Liu G-L, Chi Z, Hu Z, Chi Z-M. Genetics of trehalose biosynthesis in desert-derived Aureobasidium melanogenum and role of trehalose in the adaptation of the yeast to extreme environments. Curr Genet. 2018;64:479-91.

43. Tapia H, Young L, Fox D, Bertozzi CR, Koshland D. Increasing intracellular trehalose is sufficient to confer desiccation tolerance to Saccharomyces cerevisiae. PNAS. 2015;112:6122-7.
44. Wang Y, Song X, Zhang Y, Wang B, Zou X. Effects of nitrogen availability on polymalic acid biosynthesis in the yeast-like fungus Aureobasidium pullulans. Microb Cell Fact. 2016;15:1-12.

45. Cao Y, Peng G, He Z, Wang Z, Yin Y, Xia Y. Transformation of Metarhizium anisopliae with benomyl resistance and green fluorescent protein genes provides a tag for genetically engineered strains. Biotechnol Lett. 2007;29:907-11.

46. Jin K, Zhang Y, Fang W, Luo Z, Zhou Y, Pei Y. Carboxylate transporter gene JEN1 from the entomopathogenic fungus Beauveria bassiana is involved in conidiation and virulence. Appl Environ Microbiol. 2010;76:254-63.

47. Zhu ZW, Zhang SF, Liu HW, Shen HW, Lin XP, Yang F, Zhou YJJ, Jin GJ, Ye ML, Zou HF, Zhao ZBK. A multi-omic map of the lipid-producing yeast Rhodosporidium toruloides. Nat Commun. 2012;3:11.

48. Wei $P$, Lin M, Wang Z, Fu H, Yang H, Jiang W, Yang ST. Metabolic engineering of Propionibacterium freudenreichii subsp. shermanii for xylose fermentation. Bioresour Technol. 2016;219:91-7.

49. Wei PL, Cheng C, Lin M, Zhou YP, Yang ST. Production of poly(malic acid) from sugarcane juice in fermentation by Aureobasidium pullulans: kinetics and process economics. Bioresour Technol. 2017;224:581-9.

50. Yao R, Shimizu K. Recent progress in metabolic engineering for the production of biofuels and biochemicals from renewable sources with particular emphasis on catabolite regulation and its modulation. Process Biochem. 2013;48:1409-17.

\section{Submit your next manuscript to BioMed Central and we will help you at every step:}

- We accept pre-submission inquiries

- Our selector tool helps you to find the most relevant journal

- We provide round the clock customer support

- Convenient online submission

- Thorough peer review

- Inclusion in PubMed and all major indexing services

- Maximum visibility for your research

Submit your manuscript at www.biomedcentral.com/submit 